\title{
Fragility curve of low-to-mid-rise concrete frame retrofitted with FRP
}

\author{
Rida Handiana Devi ${ }^{1, *}$ Senot Sangadji ${ }^{2, *}$, and Halwan Alfisa Saifullah ${ }^{2}$ \\ ${ }^{1}$ Master Program in Civil Engineering, Faculty of Engineering, Universitas Sebelas Maret \\ ${ }^{2}$ Civil Engineering Department, Faculty of Engineering, Universitas Sebelas Maret
}

\begin{abstract}
In order to achieve satisfactory global seismic behaviour of a concrete fame structure and to prevent undesirable local failures of its structural element, local strengthening of structural members by means of FRP wrap is one of the cost effective retrofitting strategy. This FRP wrapped column will increase the ductility of the element as well as the capacity that in turn will allow attaining more energy dissipating global performance. This on-going research aims to demonstrate the seismic performance of Low-to-MidRise Concrete Frame retrofitted by FRP wrap in several configurations. The fragility curves of the structure before and after to local strengthening will be developed and analysed. Fragility curve will describe the probability of the structure that will exceed certain damage states given the ground shaking intensity during its service life. This curve allows evaluation for the retrofitting strategy is carried out rationally.
\end{abstract}

\section{Introduction}

In the earthquake prone region, buildings must be designed and built to resist seismic force in order to protect the inhabitants and minimize the losses. Many newly built building have attained the level of seismic resistance as it was designed based on the current building codes and standards. However, many existing building stock are quite vulnerable to seismic attacks and hence required to be strengthened to enhance their capacity, stiffness, and ductility.

Retrofitting is one strategy that is often used to reduce the risk of damage / collapse of existing buildings due to earthquakes that will probably occur during the rest of their service life. In this case, retrofitting is understood as an act of rehabilitating an existing building by modifying the existing structure and / or adding a 'technical component' which was not initially there to strengthen or improve the structure's seismic performance.

To improve the strength and ductility and to prevent collapse of reinforced concrete (RC) building frame element, seismic retrofitting by fiber reinforced polymers (FRP) confinement is the most common strategy. FRP confinement, where structural elements are coated with fiber sheets reinforced with polymer resins, may be implemented locally on the structural member with potential plastic hinges. After hardening the FRP confinements will provide restraints, adding rigidity, and increase the capacity of the element to carry load which in turn will attain better global seismic behaviour of the structures [1-3].

This reasearch aims to evaluate the seismic performance of typical low-to-mid-rise RC frame by determining its seismic fragility pre- and post FRP retrofitting actions. As fragility curve shows the probability of the building exceed certain prescribed damage states given earthquake intensity, then the efficacy of the retrofitting proposed may be determined rationally.

\section{Research method}

First step in the research is to inspect the building in question in order to describe the building configuration necessary to model and define the level of knowledge of the structure. The existing structure is typical low-to-midrise moment resisting $\mathrm{RC}$ frame for low income apartment in Indonesia. Then the retrofit strategy by applying FRP wrap was applied hypothetically to first story columns that was expected to provide an increase in building seismic capacity.

Afterwards, pushover analysis was carried out to obtained load-deformation relation of the structure pre and post retrofitting. The capacity curves yield from the procedure were then used as inputs to compute the fragility curve of the pre and post retrofitting structures.

\subsection{The $3 \mathrm{~d}$ model of existing structure}

The existing structures considered in this reasearch is Rusunawa (low income apartment) Tegalkamulyan at Cilacap, Central Java. The structure represents typical low-to-mid-rise government-owned building that functions as a dwelling for people [4].

The reinforced concrete moment resisting frame is located at 7.89 latitudes and 109.024 longitudes with Spectral Acceleration Response 0.989 for a short period and 0.391 for long-period. It is, therefore, categorized in

\footnotetext{
*Corresponding author: ridahandiana@student.uns.ac.id
} 
the moderately high seismicity. It has 4 story with irregularity in plan as depicted in Fig. 1., with various member section geometry has been found in the structure. Fig. 2 shows the 3D computer model of the moment resisting frame with pushover load.

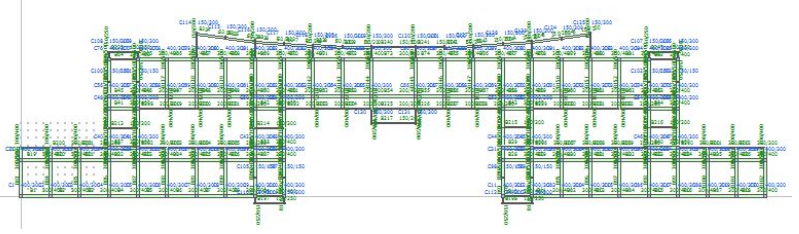

Fig 1. Structure plan of Rented Apartment in Cilacap

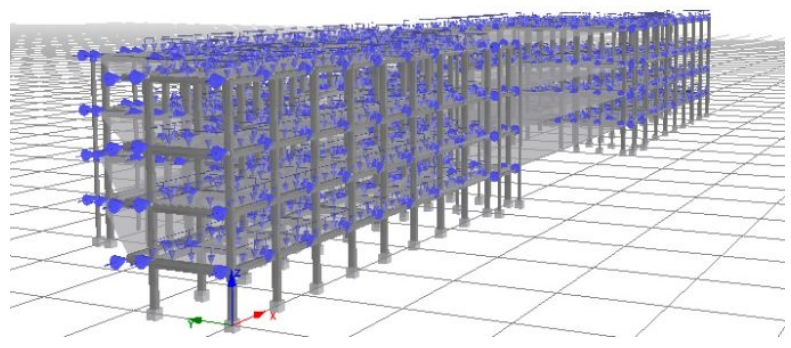

Fig 2. Non retrofitted model

In preventing soft story effect, two hypothetical FRP retrofitting strategies were employed to the first story column. First, FRP wrap for interior column which was predicted to have plastic hinges as depicted in the Fig. 3. Second, FRP wrap for the column at the perimeter as in the Fig. 4.

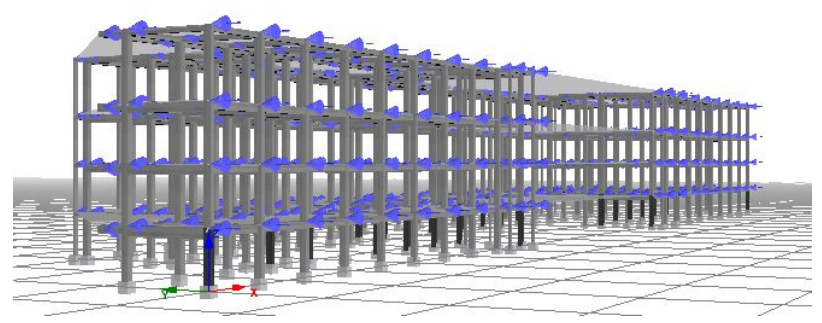

Fig 3. 3D model of FRP wrap for the column at the interior

\subsection{Structural modelling parameters}

In predicting the load-displacement response of the structure with FRP-confined element the finite element analysis was employed by means of SEISMOSTRUCT. The finite element program is capable to simulate large displacement behavior of RC frame building under static or dynamic loading. It also takes into account material inelasticity as well as geometric nonlinearities in performing many different analyses, such as eigenvalue, dynamic and static time-history, conventional and adaptive pushover, incremental dynamic analysis, and non-variable static loading. The behavior of the $3 \mathrm{D}$ computer model representing the global behavior of the structure are governed by material and geometric nonlinearities [5].

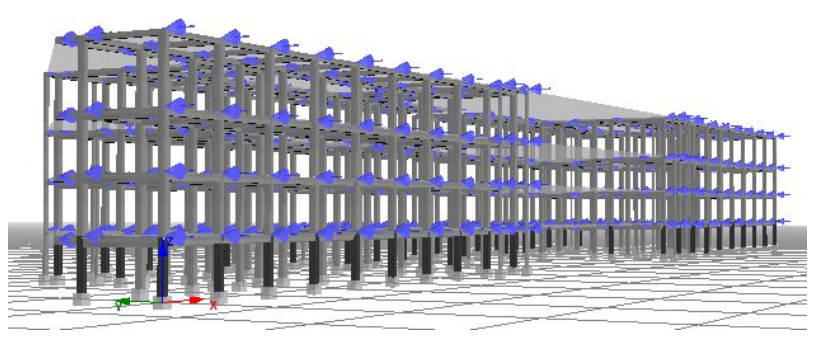

Fig 4. 3D model of FRP wrap for the column at the perimeter

The non-linear FRP confined concrete column was modeled in this FE program based on the work of Ferracuti [6]. As to accurately depict the continuous characteristic of the RC structural frame element, 'distributed plasticity' approach has been implemented in the modeling. This nonlinear modeling approach requires simply geometrical and material characteristics as input data.

In the distributed inelasticity modeling approach, the constitutive behavior of the cross section of RC members was formulated by Fiber Element Modeling (inelastic frame element) [7]. Frame element is divided into a number of segments and The Navier-Bernoulli approximation is used as delimiter. The cross sections were discretized into number of fibers in order to accurately represent the distribution of the material nonlinearity across the section area, representing unconfined concrete, confined concrete, and reinforcing bars, as depicted in the Fig. 5.

The constitutive material properties were assigned for each fiber modeling. The properties describe the nonlinear uniaxial stress-strain response of the unconfined and confined concrete, and define the longitudinal reinforcing bars post-yield strain hardening nonlinear behavior. The total stress-strain response of the cross section was obtained by integrating the nonlinear response of each individual fiber over the cross sectional area. This has been performed at appropriately selected integration cross section so-called gauss section A and B.

Finally, the global material nonlinearity of the frame is then obtained by the assembly of the contributions in stiffness and strength of the structural components. Spacone and coworkers [7] employed this flexibilitybased approach to formulate the beam-column element in FE modeling. This approach allows implicit definition of material constitutive model into the element therefore a prior moment-curvature analysis of members is not required. Furthermore, it is not expected to introduce element hysteretic response.

\subsection{Materials parameters}

Differentiating rebar, composite material, confined and unconfined concrete section, in this fiber-based modeling approach, a cross-section of FRP retrofitted RC column is divided into several fibers. The cyclic stress-strain behavior of the reinforcing bars, Fig. 5: a.2., was modelled 
by the formula proposed by Menegotto and Pinto that was modified by Fillipou to take into account isotropic hardening rules. Meanwhile, for the unstrengthen concrete, a uniaxial nonlinear cyclic stress-strain relationship followed the model proposed by Mander et al., Fig. 5: b.2 and c.2. For FRP composite materials, the stress-strain relationships are completely linear up to the failure [8].

Further, concrete with confinement effects with FRP wraps were modelled via model proposed by Spoelstra and Monti [9].

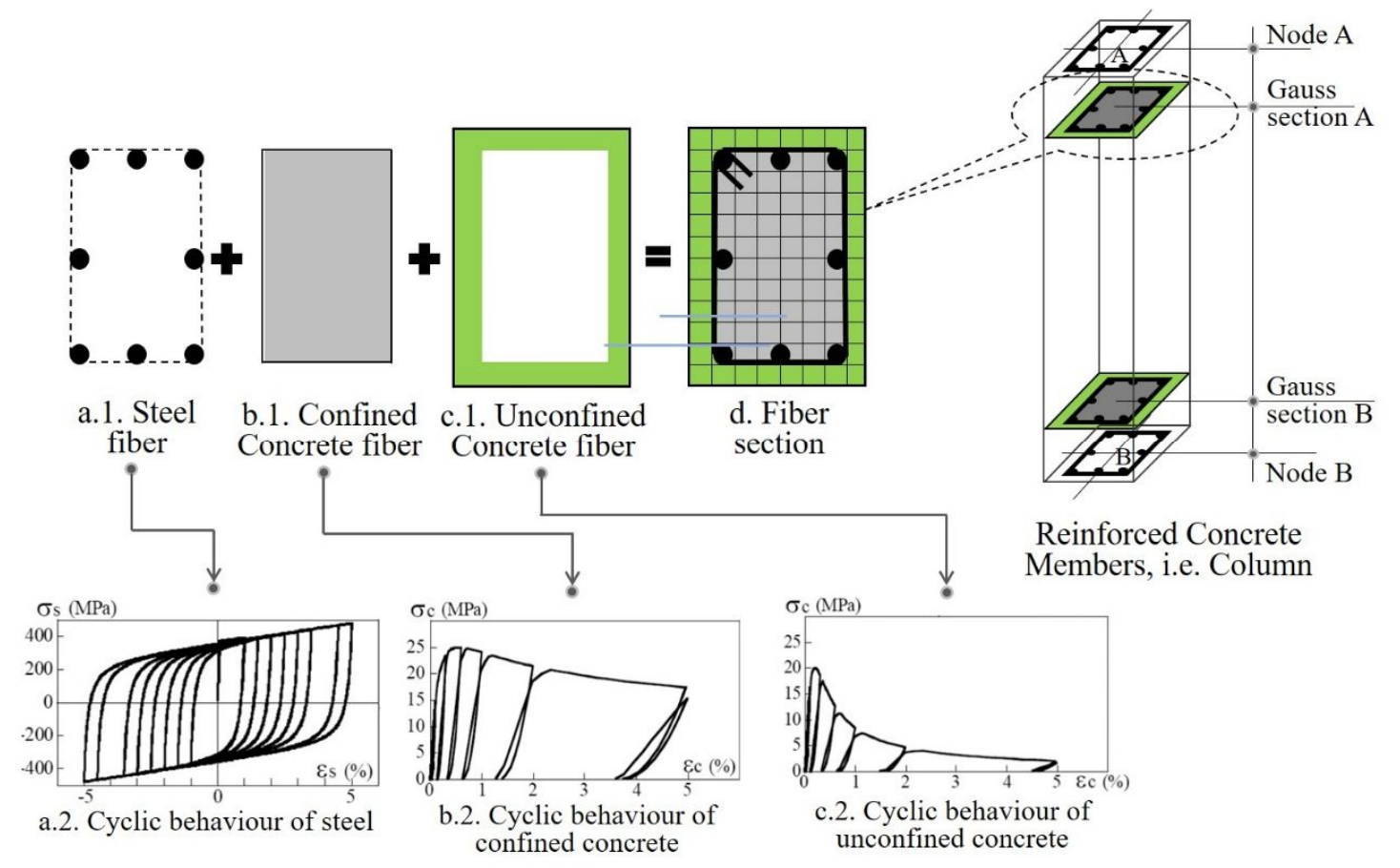

Fig 5. Fiber element approach for modelling distributed plasticity (inelastic frame element) [5, 7]

The two layers of carbon-based FRPs or CFRP (Carbon Fiber Reinforced Polymer) was implemented in the model to attain the recommended thickness of 0,17 0,83 . The CFRP selected is SikaWrap 600C with material properties as shown in Table 1:

Tabel 1. Material properties of SikaWrap 600C

\begin{tabular}{ll} 
Fiber thickness & $0,331 \mathrm{~mm}$ \\
\hline Tensile strenght & $3800 \mathrm{Mpa}$ \\
\hline Tensile Modulus & $242000 \mathrm{Mpa}$ \\
\hline Elongation & $1,55 \%$ \\
\hline Weight & $600 \mathrm{gr} / \mathrm{m}^{2}$
\end{tabular}

\subsection{Nonlinear geometry}

The geometric nonlinearities (local and global) were automatically taken into account by the program during the analysis [5].

\subsection{Nonlinear static (pushover) analysis}

The nonlinear static analysis, commonly known as pushover analysis, permit engineer to take into account nonlinear behavior of the structure by applying an prescribed incremental static loading pattern in the lateral direction at the beam column nodes in the structural models. This simple technique simulates the inertia forces induced by a single horizontal component of the seismic action [10].

Two sets of monotonically increasing lateral forces (uniform and modal pattern) might be applied at the location of the masses at each floor. The resulting information is able to describe the inelastic response of the building, the evolution of plastic mechanism and structural damage, as a function of the lateral loads and its corresponding horizontal displacements. The final result of this pushover method is a capacity curve describing base shear force as a function of displacement [11].

Each point of the curve delineates a specific damage state (limited damage, severe damage and collapse) for the structure. This can be done due to the fact that the deformation for all components can be related to the global displacement of the structure.

\subsection{Fragility Function}

Fragility curve characterizes the probability of the structure that will exceed certain damage states given the demand parameter during its service life. This demand parameter, also known as ground-shaking intensity, may be Peak Ground Acceleration (PGA), Peak Ground Velocity (PGV) or spectral displacement for a certain period.

The relationship between ground-shaking intensity (engineering demand parameter, EDP) and the 
probability that the structure (system) reaching, or exceeding, a response limit state (or damage state, DS) is defined as fragility function. Its conditional probability may be expressed as log-normal cumulative distribution equation [4] as follows

$$
P_{f}\left[d_{s} \geq d_{s i} \mid I M\right]=\Phi\left[\frac{1}{\beta_{d s}} \ln \left(\frac{I M}{I M_{m i}}\right)\right]
$$

where $\mathrm{P}_{\mathrm{f}}$ is the conditional probability of being or exceeding a particular damage sate, DS, for earthquake intensity measure, IM, $\phi$ is the standard cumulative function, $\mathrm{IM}_{\mathrm{mi}}$ is the median value of earthquake intensity which cause the $\mathrm{i}^{\text {th }}$ damage state, and $\beta$ tot is the dispersion representing total standard deviation. Earthquake intensity parameters, IM, may be include peak ground acceleration/velocity/displacement, spectral acceleration, spectral velocity or spectral displacement. In this paper spectral displacement, $\mathrm{Sd}$ is chosen to be the earthquake intensity parameters as easy means to relates with damage level.

\section{Results and discussions}

\subsection{Capacity Curve}

The structural response due to pushover loading may be expressed as a force - deformation curve or called a capacity curve. This curve explains the relationship between the base shear and displacement which is usually viewed at the roof displacement. Fig. 6 shows capacity curve representing the response of the structure subject to pushover load. Three curves show the response of the non-retrofitted structure, retrofitted with FRP on the all perimeter first story columns, and the structures retrofitted with FRP in the first story interior column which experience plastic hinges (first yield).

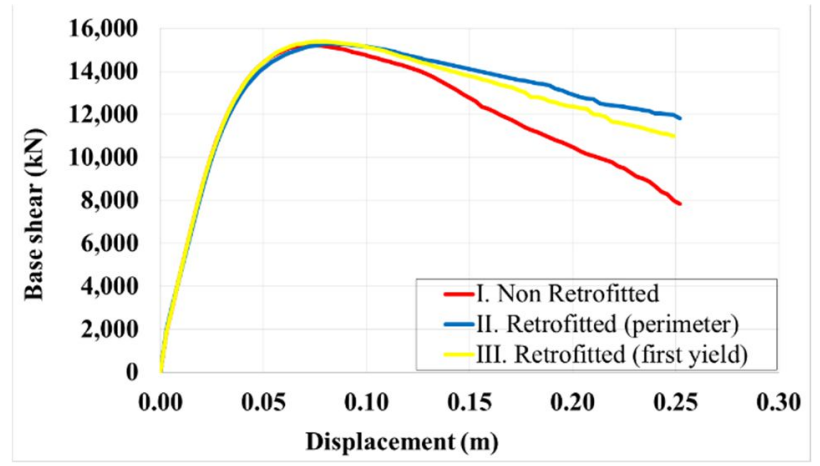

Fig 6. Capacity curve

Fig 6 represents the capacity curve by static pushover analysis modelled as non retrofitted, retrofitted with FRP by perimeter, and retrofitted with FRP by first yield. The curve show that the non-retrofitted structure exhibit a greater decrease in shear capacity compared to the retrofitted even though the the base shear reach almost the same peak value.

The two retrofitted models also show different results because the perimeter application of retrofit to buildings shows higher shear capacity. Structure with retrofit exhibit higher post elastic capacity. The three models are able to withstand lateral loads with a small difference of $15,2 \times 10^{3} \mathrm{kN}$ for non retrofitted models, $15,3 \times 10^{3} \mathrm{kN}$ retrofit perimeter, and retrofit first yield $15,4 \times 10^{3} \mathrm{kN}$.

\subsection{Spectrum Capacity}

\subsubsection{Comparison of Spectrum Capacity Method}

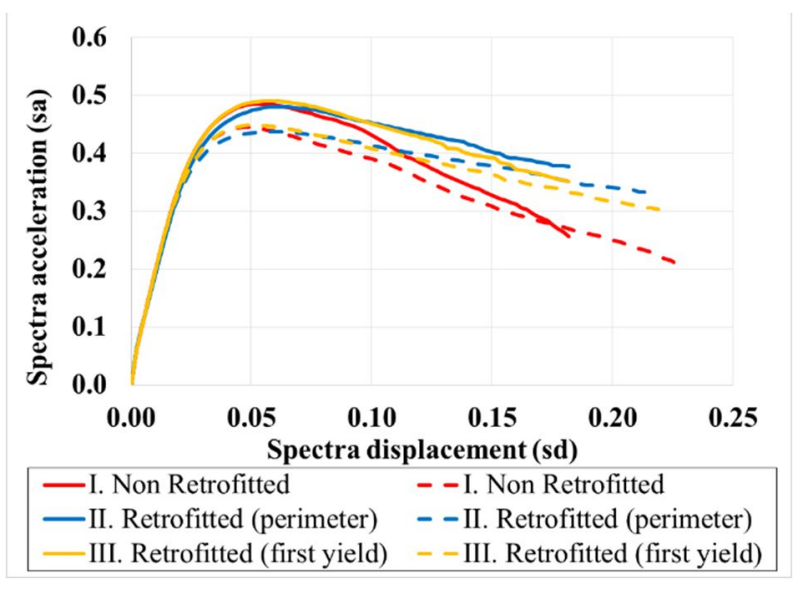

Fig 7. Comparation of Idealisation convertion method and Perstep convertion method

\subsubsection{Damage States}

The performance levels of a structures can be determined by defining threshold of damage (limit) states. These limit states delineate the boundary between damage levels of a structure as consequence of earthquake. Qualitatively, the most common classifications of damages are the following: no damage; slight/minor; moderate; extensive; complete. Yet, discrete damage scale expressed numerically is usually required for constructing fragility curves. Then, building fragility curves are expressed as lognormal functions which represent the probability of reaching prescribed damage states given median estimates of spectral response. In this work spectral displacement, Sd, was used.

Two method of determining damages states were used in this work; HAZUS MH-MR5 and Silva et al [12]. HAZUS MH-MR5 classifies the limit of damage in slight, moderate, extensive, and complete. The threshold of the damage states corresponds to the median value of the demand parameter (e.g., spectral displacement, $\mathrm{Sd}$ ) is shown in the table 4.

Tabel 4. Damage states (Sd)

\begin{tabular}{lccc} 
Damage & \multicolumn{3}{c}{ Sd } \\
\cline { 2 - 4 } levels & $\begin{array}{c}\text { Non } \\
\text { retrofitted }\end{array}$ & $\begin{array}{c}\text { Retrofitted } \\
\text { (Perimeter) }\end{array}$ & $\begin{array}{c}\text { Retrofitted } \\
\text { (first yield) }\end{array}$ \\
\hline Slight & 0,01840 & 0,01868 & 0,01840 \\
\hline Moderate & 0,03680 & 0,03736 & 0,03680 \\
\hline Extensive & 0,09199 & 0,09340 & 0,09201 \\
\hline Complete & 0,21464 & 0,21793 & 0,21468
\end{tabular}

Meanwhile, Silva et al [12] proposed maximum base shear corresponds with displacement point to be used as 
damage states. Limit States 1 (LS1) is determined when the roof displacement has reached the maximum base shear, Limit states 2 (LS2) it is determined as the displacement at maximum base shear, while Limit States 3 (LS3) is defined by spectral displacement when $80 \%$ of maximum post peak base shear is reached. Table 5 shows the recap of the damage (limit) states as proposed by Silva et al.

Tabel 5. Damage states (Sd)

\begin{tabular}{ccccccc}
$\begin{array}{c}\text { Condi- } \\
\text { tion }\end{array}$ & \multicolumn{6}{c}{ Sd } \\
\cline { 2 - 7 } & Non retrofitted & \multicolumn{2}{c}{$\begin{array}{c}\text { Retrofitted } \\
\text { (Perimeter) }\end{array}$} & \multicolumn{2}{c}{$\begin{array}{c}\text { Retrofitted } \\
\text { (first yield) }\end{array}$} \\
\hline & $\Delta$ & Sd & $\Delta$ & Sd & $\Delta$ & Sd \\
\hline LS1 & 0.030 & 0,022 & 0,027 & 0,02 & 0,03 & 0,022 \\
\hline LS2 & 0.075 & 0,054 & 0,084 & 0,062 & 0,087 & 0,063 \\
\hline LS3 & 0,162 & 0,118 & 0,231 & 0,171 & 0,204 & 0,149
\end{tabular}

In developing fragility of existing structure, variability in the nature of earthquake event (aleatoric uncertainty) and in the model (epistemic uncertainty) must be taken in to account by calculating the standard deviation of uncertainty $(\beta)$ : standard deviation of spectrum demand uncertainty $\left(\beta_{d}\right)$, standard deviation of spectrum structural capacity $\left(\beta_{c}\right)$, standard deviation of damage states value $\left(\beta_{\mathrm{M}(\mathrm{ds})}\right)$. The total standard deviation may be defined by equation 2 .

$$
\beta_{d s}=\sqrt{\left[\left(\operatorname{CONV}\left[\beta_{c}, \beta_{d}\right]\right)\right]^{2}+\left[\beta_{M(d s)}\right]^{2}}
$$

\subsubsection{Discussion}

The capacity curves show the load - displacement behaviour of the structures in which it can be seen that retrofitted models may withstand almost the same maximum lateral load of $15 \times 10^{3} \mathrm{kN}$. It indicates that the application of FRP may increase the structural capacity therefore extend the collapse point. Model retrofitted at all the first story perimeter columns shows the largest base shear when the target displacement is achieved. The capacity curves, then, was converted into spectrum capacity relating spectral acceleration and spectral displacement. In this work, spectral displacement would be used as the demand parameter for construction fragility curves.

A set of fragility curves of non-retrofitted (NR) and retrofitted at few columns which suffer first yield (Rfy) and retrofitted all perimeter columns in the first story (Rper) structural model which was developed based on the HAZUS damage sates is shown in the Fig. 8. Each fragility curve predicts whether the damage meets or exceeds a certain damage states, Slight, Moderate, Extensive, and Complete defined by HAZUS. Fig. 9 show the fragility curves describing the probability that the structure will reach prescribed damage (limit) states defined by Silva et al. The level of fragility based on the maximum base shear seems more representative as it shows the influence of FRP on the probability of structure damage exceedance in LS2 and LS3. It can be identified that the non retrofit structure model is more fragile than the retrofitted model.

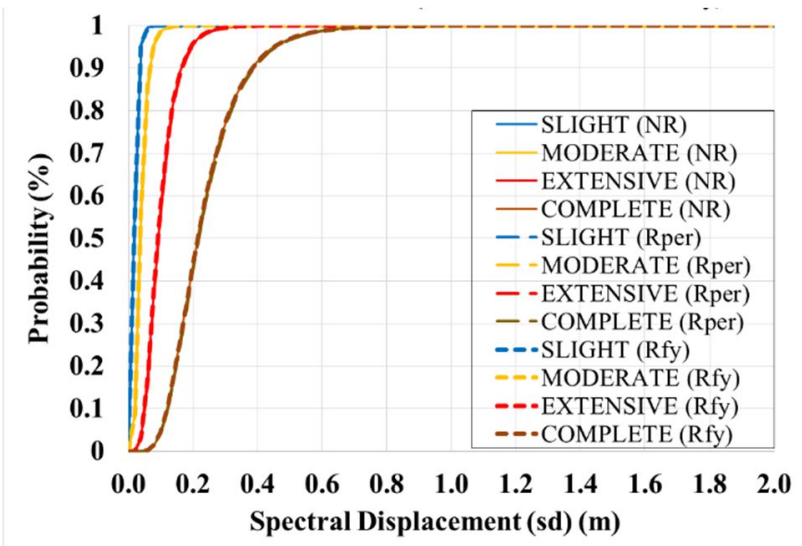

Fig 8.Fragility curve (HAZUS MH-MR5)

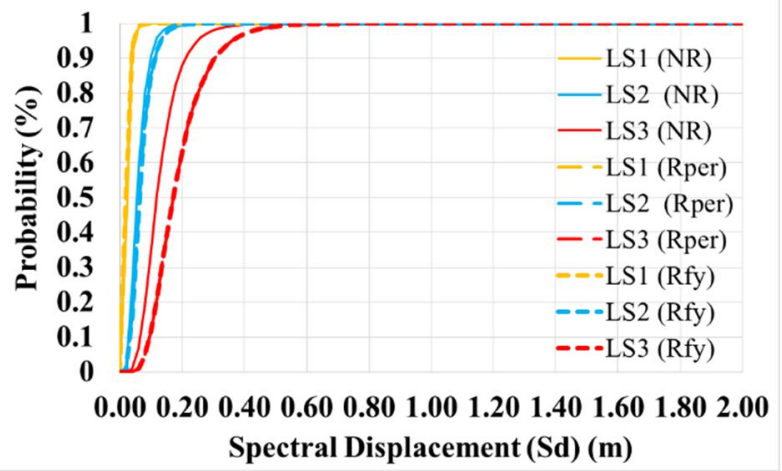

Fig 9 .Fragility curve (SILVA et al,2012)

\section{Conclusions}

The development of the fragility curves of the nonretrofitted and retrofitted building model has been done by determining structural response due to quasi-static seismic loading. The response was then transformed into fragility curve describing conditional probability that the structure will reach certain damage level given various ground shaking intensity.

The fragility curve may be used to assess rationally the seismic performance of the structure. The structure retrofitted with FRP wrap may alter its fragility by lowering its probability to exceed prescribed limit states. This information certainly will help the stakeholders to rationally decide whether to implement structural intervention to reduce building seismic risk.

\section{References}

1. Daniel A. Pohoryles, J. Compos. Constr. 23(4): 03119001 (2019)

2. Amran, Y. H. M., et al. Properties and applications of FRP in strengthening RC structures: A review, 16 (July), 208-238. (2018)

3. ACI 440.2R-17. Guide for the Design and Construction of Externally Bonded FRP System for Strengthening Concrete Structures. (2017) 
4. Hapsari, Isyana R., Sangadji, Senot., Kristiawan Stefanus Adi., The 4th ICRMCE, MATEC Web Conf., 195 (2018)

5. Bhowmik, Tamali., FRP-Confined Capsule-Shaped Columns under Axial and Lateral Loadings. PhD Thesis, NUS (2011)

6. Ferracutti, Barbara., et al., Push-Over Analysis of FRP-Retrofitted Existing RC Frame Structure, FRPRCS-8, (2007)

7. Spacone, Enrico., Filippou, Filip C., A Fiber BeamColumn Element for Seismic Response Analysis of Reinforced Concrete Structures., Report No. UCB/EERC-91/17, Earthquake Engineering Research Center, (1991)
8. Fragiadakis, Michalis., Pinho, Rui., Antoniou, Stelios., ECCOMAS Thematic Conf. on Comp. Meth. in Str. Dyn. and Eq. Eng. (2007)

9. Marijn R. Spoelstra, Giorgio Monti, J. Compos. Constr. 3:143-150. (1999).

10. Pinho, Rui., C. Casarotti., Antoniou, Stelios., Earthquake Eng. Struct. Dyn. 36:1347-1362. (2007)

11. Jing, Wu. et al., J of Earthq Engg, 15:664-683, (2011)

12. Silva, V., Varum, H., Crowley, H., Sousa, R., Pinho, R., 15 WCEE Lisboa (2012) 